\title{
Lean Breed Landrace Pigs Harbor Fecal Methanogens at Higher Diversity and Density than Obese Breed Erhualian Pigs
}

\author{
Yu-heng Luo, ${ }^{1}$ Yong Su, ${ }^{1,2}$ André-Denis G. Wright, ${ }^{3}$ Ling-li Zhang, ${ }^{1,2}$ \\ Hauke Smidt, ${ }^{1,2}$ and Wei-yun $\mathrm{Zhu}^{1}$ \\ ${ }^{1}$ Laboratory of Gastrointestinal Microbiology, College of Animal Science and Technology, Nanjing Agricultural University, \\ Nanjing 210095, China \\ ${ }^{2}$ Laboratory of Microbiology, Wageningen University, Dreijenplein 10, $6703 \mathrm{HB}$ Wageningen, The Netherlands \\ ${ }^{3}$ Department of Animal Science, University of Vermont, 570 Main Street, Burlington, VT 05405, USA
}

Correspondence should be addressed to Wei-yun Zhu, zhuweiyun@njau.edu.cn

Received 26 February 2012; Revised 25 April 2012; Accepted 28 May 2012

Academic Editor: Yoshizumi Ishino

Copyright (๑) 2012 Yu-heng Luo et al. This is an open access article distributed under the Creative Commons Attribution License, which permits unrestricted use, distribution, and reproduction in any medium, provided the original work is properly cited.

\begin{abstract}
The diversity of fecal methanogens of Erhualian (obese type) and Landrace (lean type) pigs was examined using separate 16S rRNA gene libraries for each breed. A total of 763 clones were analyzed; 381 from the Erhualian library and 382 from the Landrace library were identified belonging to the genus Methanobrevibacter. Others were identified belonging to the genus Methanosphaera. The two libraries showed significant differences in diversity $(P<0.05)$ and composition $(P<0.0001)$. Only two operational taxonomic units (OTUs) were found in both libraries, whereas six OTUs were found only in the Erhualian library and 23 OTUs were found only in the Landrace library. Real-time PCR showed that the abundance of fecal methanogens in Landrace pigs was significantly higher than that in Erhualian pigs $(P<0.05)$. Results showed that the Landrace pig (lean) harbored a greater diversity and higher numbers of methanogen mcrA gene copies than the Erhualian pig (obese). These differences may be related to the fatness or leanness in these two pig breeds. The results provide new leads for further investigations on the fat storage of pigs or even humans.
\end{abstract}

\section{Introduction}

Methanogenic archaea exist widely in the gastrointestinal (GI) tract of many vertebrates and invertebrates including humans [1-3]. Methanogens can use hydrogen and other products such as formate, methanol, acetate to reduce carbon dioxide to methane. Methane formation not only contributes to global warming as a greenhouse gas, but also represents an energy loss for the animal.

Pigs were estimated to typically lose $1.2 \%$ of ingested energy due to methane formation [4]. Furthermore, it was shown in a germ-free mouse model that methanogens play an important role in energy metabolism and adipose deposition through the re-colonization or co-colonization of the human fecal isolate Methanobrevibacter smithii and Bacteroides thetaiotaomicron into the GI tract of mice $[5,6]$. Further research in humans showed that the diversity of $M b b$. smithii concentration was higher in anorexic patients than in a lean population [7]. It was also reported that the GI tract microbiota from obese individuals was depleted in $M b b$. smithii [8].

Archaea in the human GI tract comprise mainly members of the order Methanobacteriales, which are $\mathrm{H}_{2}$-oxidizing methanogens. Interestingly, the number of $\mathrm{H}_{2}$-utilizing methanogens was significantly higher in obese individuals than in lean or postgastric-bypass individuals [9]. These reports may suggest some relationship between the composition and abundance of GI tract methanogenic communities, and the host's energy metabolism, which subsequently relates to the fatness or leanness of the host.

Pigs share a high similarity with humans with respect to the anatomy, physiology and metabolism of the digestive system [10]. Thus, the composition of GI tract microbiota of obese and lean pigs could reflect that of corresponding human phenotypes. Erhualian and Landrace breeds are typically obese and lean pigs [11-14], respectively, thus their energy metabolism might be distinctive. Erhualian pig, a sister breed to Meishan (both belonging to Taihu pig), 
is a local porcine breed mainly located around the Taihu Lake area of China and is characterized by increased fat storage, tasty meat quality and high fertility [15]. In contrast, Landrace is an "alien" breed, which is usually used as a sire in the breeding of commercial pork production for the breed's high growth rate and lean meat percentage. According to previous research described above, the distinction between the two breeds may be partially contributed by their different gut microbiota. Recently, it has been found that obese Meishan pigs showed an increased relative abundance of Firmicutes and lower numbers of Bacteroidetes [16], in line with several reports from humans as described above. Although the diversity and abundance of bacteria between obese and lean pigs have been shown to vary $[12,16]$, there is no evidence has been shown regarding the variation of intestinal methanogens between the two phenotypes. Considering the key role of gut methanogens during the microbial fermentation, we hypothesized that the two breeds will have different composition and density of GI tract methanogens.

Therefore, this study investigated the phylogenetic diversity and community structure of methanogens in the feces from Erhualian (obese) and Landrace (lean) pigs by analyzing $16 \mathrm{~S}$ rRNA gene sequences from two clone libraries, one for each breed. In addition, the density of methanogens was quantified by real-time PCR targeting the morA gene. The results shown here could provide new leads towards understanding and control of the role of GI tract microbiota in fat storage of pigs and potentially humans.

\section{Material and Methods}

2.1. Sample Sources and Processing. All Erhualian and Landrace pigs were raised at a commercial farm in Jiangsu Province using the same feed and under the same environmental conditions. Piglets were weaned 45 days after birth. Fecal samples from 3 suckling ( $40 \mathrm{~d}$ ) piglets, 4 weaned $(50 \mathrm{~d})$ pigs, 4 growing $(70 \mathrm{~d})$ pigs, and 4 sows (11 to 12 months) of Erhualian breed, and 4 suckling piglets, 3 weaned pigs, 3 growing pigs, and 4 sows of Landrace breed were collected. Animals were randomly selected from different litters. Approximately $10 \mathrm{~g}$ of feces from each pig was collected into a sterilized $15 \mathrm{~mL}$ centrifuge tube and stored at $-20^{\circ} \mathrm{C}$ until further processing.

\subsection{DNA Extraction, PCR Amplification, and Clone Library} Construction. Nucleic acids were extracted from $0.5 \mathrm{~g}$ of fecal material, based on the bead-beating method described by Zoetendal et al. [17]. The extracted DNA was purified with a PCR Clean-Up system (Promega, USA) and stored at $-20^{\circ} \mathrm{C}$.

Primers Met86F and Met1340R were used to amplify archaeal 16S rRNA genes [18]. The amplification was initiated with a denaturation at $94^{\circ} \mathrm{C}$ for $3 \mathrm{~min}$, then followed by 40 cycles of $94^{\circ} \mathrm{C}$ for $30 \mathrm{~s}, 58^{\circ} \mathrm{C}$ for $30 \mathrm{~s}, 72^{\circ} \mathrm{C}$ for $90 \mathrm{~s}$, and a final extension at $72^{\circ} \mathrm{C}$ for $10 \mathrm{~min}$. The $\mathrm{PCR}$ reaction mixture $(50 \mu \mathrm{L})$ consisted of $200 \mathrm{nM}$ of each primer, approximately $0.35 \mu \mathrm{g}$ of template DNA, $1 \times$ Taq reaction buffer, $200 \mu \mathrm{M}$ of each dNTP, $2 \mathrm{mM}$ of $\mathrm{MgCl}_{2}$ and four units of Taq DNA polymerase. The product was purified using a PCR CleanUp system (Promega, USA).

To construct 16S rRNA gene clone libraries, equal quantities of purified PCR products from animals of same breed (i.e., Erhualian, Landrace) were pooled. Cloning of pooled amplicons into Escherichia coli TOP10 using the pGEM-T Easy vector (Promega, USA), and screening of transformants using RFLP analysis of the cloned 16S rRNA genes by restriction digestion with endonucleases Hae III, Alu I and Hра II, was done as described previously [19]. Clones with identical RFLP patterns were defined as one phylotype. One representative clone from each RFLP pattern was sequenced in both directions commercially (Invitrogen, China).

\subsection{Estimation of Archaeal Diversity and Phylogenetic Anal-} $y$ sis. Based on a species-level sequence identity criterion of 98\% [20], MOTHUR [21] was used to assign sequences across the two libraries to operational taxonomic units (OTUs). As part of the MOTHUR suite of programs, Shannon Index was used to analyze diversity and Libshuff analysis was used to compare population structure between the two libraries. The sampling effort in each library for species-level OTUs was evaluated by calculating the coverage (C) according to the equation $C=1-(n / N)$, where $n$ is the number of OTUs represented by a single clone and $N$ is the total number of clones analyzed in the library [22]. GenBank's BLAST program [23] was used to presumptively identify the nearest validly described neighbor of each methanogen sequence. Lastly, a neighbor-joining tree was constructed using the phylogenetic software PHYLIP (ver 3.69) with 1,000 bootstrap resamplings [24].

\subsection{Quantification of Total Fecal Methanogens of Each Breed} by Real-Time PCR. The abundance of fecal methanogens was determined with real-time PCR using an Applied Biosystems 7300HT Real-Time PCR System (Applied Biosystems, CA, USA). Primers targeting the $m c r A$ gene [25] were used for the specific detection of methanogenic archaea. DNA samples extracted from each fecal sample of each breed (total 15 Erhualian pigs and 14 Landrace pigs) as described above were used for the real-time PCR amplification of morA gene. DNA from cells of a pure culture of Methanobrevibacter smithii supplied by CSIRO Livestock Industry (Brisbane, Australia) was also extracted with a Genomic DNA Purification Kit (Promega, USA). The concentrations of the above DNA samples extracted from fecal materials, or from cells of the pure culture, were determined in triplicate with a NanoDrop ND-1000 UV Spectrophotometer (NanoDrop Technologies, USA) and the mean values were calculated. Serial dilutions of DNA extracted from Methanobrevibacter smithii cells were used to generate a standard curve. A reaction mixture $(10 \mu \mathrm{L})$ consisted of $5 \mu \mathrm{L}$ of IQ SYBR Green Supermix (Roche, Basel, Switzerland), $0.5 \mu \mathrm{L}$ of each primer $(10 \mu \mathrm{M})$, and $1 \mu \mathrm{L}$ of template DNA $(100 \mathrm{ng} / \mu \mathrm{L})$. PCR was performed with an initial denaturation step of $94^{\circ} \mathrm{C}$ for $2 \mathrm{~min}$, followed by 30 cycles of $94^{\circ} \mathrm{C}$ for $30 \mathrm{~s}, 60^{\circ} \mathrm{C}$ for $15 \mathrm{~s}$ and $68^{\circ} \mathrm{C}$ for $1 \mathrm{~min}$. 
Differences in the abundance of total fecal methanogens between Erhualian and Landrace pigs were tested for significance with an One-Sample $t$-test method using the statistical software SPSS 16.0. Differences were considered significant when $P<0.05$.

2.5. Nucleotide Sequences and Accession Numbers. Phylotypes were designated by using the prefix LGM (Laboratory of Gastrointestinal Microbiology) followed by either "Er" or "La" to represent the two pig breeds, Erhualian and Landrace, respectively; a number to indicate the unique phylotype (e.g., phylotype 7 from the Erhualian pig breed is LGM-Er7).

The nucleotide sequences reported in this paper have been deposited in the GenBank database under accession numbers. HM573393 to HM573406 (Erhualian) and HM573407 to HM573449 (Landrace).

\section{Results}

3.1. The Density of Total morA Gene Copies in the Feces of the Two Breed Pigs. Quantitative real-time PCR showed that the number of $m c r A$ gene copies in the feces of Landrace pigs $8.80 \pm 0.91(\log 10(\mathrm{mcrA}$ gene copies per gram of wet weight)) was significantly higher than that in the Erhualian pigs $(8.23 \pm 0.63, P<0.05)$.

3.2. Sequence Analysis of the Two Archaeal 16S rRNA Gene Clone Libraries. A total of 381 cloned archaeal 16S rRNA gene amplicons, obtained from fecal samples taken from Erhualian pigs at different life stages, were analyzed. Sequence examination of these clones revealed eight different OTUs (Table 1). The majority of sequences (368/381) were most closely related to members belonging to the genus Methanobrevibacter with sequence identities ranging from $96.9 \%$ to $99.9 \%$. One hundred and forty-one sequences (37\%) were assigned to OTU11 (Table 2) and related to Methanobrevibacter gottschalkii and Methanobrevibacter millerae, while 111 sequences (29\%) were assigned to OTU13 and related to Methanobrevibacter smithii (Table 2). Clone LGM-Er7 (OTU2) was distantly related to Methanobrevibacter millerae with $96.9 \%$ identity, but had $97.7 \%$ identity to uncharacterized Methanobrevibacter clones from the foregut of the Tammar wallaby [26]. LGM-Er8 (OTU3) was related to Methanobrevibacter ruminantium (97.1\% identity), but had $99.8 \%$ identity to clones from a coculture with anaerobic fungi (Cheng et al., unpublished data). Only clone LGMEr4 (OTU1) was distantly related to Methanosphaera cuniculi ( $96.3 \%$ identity). OTUs $1,2,3,4,5$, and 6 were unique to the Erhualian library (Tables 1 and 2; Figure 1).

The 16S rRNA gene library from Landrace pigs was comprised a total of 382 clones, consisting of 25 OTUs (Table 1). Most of sequences (227/382) were related to members belonging to the genus Methanobrevibacter with sequence identities ranging from $93.9 \%$ to $99.5 \%$. Eightynine sequences (23\%) were assigned to OTU13 and related to Methanobrevibacter smithii, while 81 sequences $(21 \%)$ were assigned to OTU20 and related to Methanosphaera cuniculi (Tables 1 and 2). LGM-La2 (OTU20), LGM-La23 (OTU20), and LGM-La38 (OTU26) showed 97.6\%, 97.4\%, and 97.4\% identity to Methanosphaera cuniculi, respectively, but had even higher $(99.8 \%, 99.6 \%$, and 99.1\%) sequence identities to uncharacterized clones from pig feces [27]. Although LGM-La3 (OTU7) had 95.3\% identity to Methanobrevibacter millerae it had $97 \%$ identity to unidentified clones from the Holstein and Jersey dairy cows in the USA [28]. LGMLa29 (OTU19) showed $97.1 \%$ to Methanosphaera stadtmanae and had $97.4 \%$ to sequences from rumen of goats (Pei unpublished data). LGM-La33 (OTU21) was distantly related to Methanosphaera cuniculi with 95.5\% identity, but had $97.1 \%$ identity to clones from pig feces [27]. LGMLa40 was found $96.8 \%$ identity related to Methanobrevibacter smithii, but had (OTU28) 98.2\% identity to clones from the rumen of Norwegian reindeer [29]. LGM-La1 (OTU17), LGM-La27 (OTU18), LGM-La35 (OTU23), and LGMLa11 (OTU17) were related to Methanobrevibacter smithii and Methanosphaera cuniculi with $93.8 \%-94.9 \%$ identity, but had $95.7 \%-96.8 \%$ identity to clones from lactating dairy cows in Canada [30]. LGM-La21 (OTU15), LGMLa36 (OTU24), and LGM-La37 (OTU25) were related to Methanosphaera cuniculi with $94.2 \%-95.5 \%$ identity, but had $95.3 \%-96.8 \%$ identity to clones from pig feces [27]. LGM-La12 (OTU8) and LGM-La14 (OTU10) had $93.9 \%$ and 95.1\% identity, respectively, to Methanobrevibacter smithii and Methanosphaera cuniculi, but had only $96.0 \%$ and $96.9 \%$ identity to clones from the crops of Opisthocomus hoazin, a folivorous bird from Venezuela [20]. LGM-La4 (OTU16) and LGM-La22 (OTU16) showed $95.5 \%$ and $95.7 \%$ identity related to Methanosphaera stadtmanae, but had $96.8 \%$ and $96.9 \%$ identity to clones from Jinnan cattle (Pei et al., unpublished data). LGM-La42 (OTU30) and LGMLa43 (OTU31) were distantly related to Methanosphaera cuniculi and Methanobrevibacter smithii with $95.3 \%$ identity, respectively, but had only $96.3 \%$ and $96.2 \%$ to their nearest neighbor, clones from the Holstein and Jersey dairy cows [28]. It is important to note that OTUs except OTU11 and OTU13 were only found in this library (Table 1, Figure 1).

\section{Discussion}

Anecdotal evidence from a limited number of previous studies indicated that methanogens in the hindgut of monogastric animals may play a critical role in their host's energy metabolism and adipose deposition as revealed by inoculating human-derived methanogens into a germ free mouse model [5]. However, due to its particular growth environment and the intricate syntrophic interactions with other intestinal bacteria, culture-dependent methods provide limited information on methanogens in the gut. Numerous studies using culture-independent methods including $16 \mathrm{~S}$ rRNA gene clone library analysis, have reported data on methanogen diversity and abundance in the rumen [19, $25,31,32]$. However, very little information is available on the diversity and abundance of methanogenic archaea in the gut of monogastric animals including humans and pigs. The present study used Erhualian and Landrace pigs as surrogate models for obese and lean host phenotypes and provided 
TABLE 1: 16S rRNA sequences from feces of Erhualian and Landrace pigs.

\begin{tabular}{|c|c|c|c|c|c|}
\hline \multicolumn{3}{|c|}{ Erhualian } & \multicolumn{3}{|c|}{ Landrace } \\
\hline $16 \mathrm{~S}$ phylotypes & No. clones & OTU $^{\#}$ & 16S phylotypes & No. clones & $\mathrm{OTU}^{\#}$ \\
\hline LGM-Er1 & 19 & 11 & LGM-La1 & 11 & 17 \\
\hline LGM-Er2 & 49 & 11 & LGM-La2 & 15 & 20 \\
\hline LGM-Er3 & 6 & 11 & LGM-La3 & 5 & 7 \\
\hline LGM-Er4 & 13 & 1 & LGM-La4 & 12 & 16 \\
\hline LGM-Er5 & 4 & 11 & LGM-La6 & 2 & 20 \\
\hline LGM-Er6 & 7 & 11 & LGM-La7 & 6 & 19 \\
\hline LGM-Er7 & 5 & 2 & LGM-La8 & 25 & 20 \\
\hline LGM-Er8 & 81 & 3 & LGM-La9 & 2 & 20 \\
\hline LGM-Er9 & 6 & 11 & LGM-La10 & 2 & 20 \\
\hline LGM-Er10 & 15 & 4 & LGM-La11 & 8 & 17 \\
\hline LGM-Er11 & 50 & 11 & LGM-La12 & 6 & 8 \\
\hline LGM-Er12 & 6 & 5 & LGM-La13 & 4 & 9 \\
\hline LGM-Er13 & 9 & 6 & LGM-La14 & 5 & 10 \\
\hline \multirow[t]{26}{*}{ LGM-Er14 } & 111 & 13 & LGM-La15 & 4 & 11 \\
\hline & & & LGM-La16 & 2 & 12 \\
\hline & & & LGM-La19 & 89 & 13 \\
\hline & & & LGM-La20 & 43 & 14 \\
\hline & & & LGM-La21 & 5 & 15 \\
\hline & & & LGM-La22 & 5 & 16 \\
\hline & & & LGM-La23 & 2 & 20 \\
\hline & & & LGM-La24 & 5 & 20 \\
\hline & & & LGM-La25 & 11 & 20 \\
\hline & & & LGM-La27 & 2 & 18 \\
\hline & & & LGM-La28 & 2 & 20 \\
\hline & & & LGM-La29 & 4 & 19 \\
\hline & & & LGM-La30 & 4 & 20 \\
\hline & & & LGM-La31 & 10 & 20 \\
\hline & & & LGM-La32 & 1 & 20 \\
\hline & & & LGM-La33 & 12 & 21 \\
\hline & & & LGM-La34 & 7 & 22 \\
\hline & & & LGM-La35 & 6 & 23 \\
\hline & & & LGM-La36 & 6 & 24 \\
\hline & & & LGM-La37 & 2 & 25 \\
\hline & & & LGM-La38 & 3 & 26 \\
\hline & & & LGM-La39 & 1 & 27 \\
\hline & & & LGM-La40 & 46 & 28 \\
\hline & & & LGM-La41 & 2 & 29 \\
\hline & & & LGM-La42 & 4 & 30 \\
\hline & & & LGM-La43 & 1 & 31 \\
\hline
\end{tabular}

the first account on the comparison of methanogen diversity and abundance in feces of host species with either an obese or lean phenotype. Fecal samples were collected from each breed pigs at four different ages to make the result more representative, as it was expected to cover the whole growth stages of each breed.

Real-time PCR results showed that Landrace pigs had significantly more mcrA gene copies than Erhualian pigs $(P<0.05)$, which suggests that there are more numbers of methanogens harboring in the hindgut of Landarce pigs. Moreover, Landrace pigs exhibited significantly more methanogen diversity $(P<0.05)$ than Erhualian pigs (Table 3). Libshuff analysis also indicated that differences in the community structure between the two libraries were significant $(P<0.0001)$. Clone library OTU coverages were estimated at $100 \%$ and $99.2 \%$ for Erhualian and Landrace pigs, respectively (Table 3 ). This indicates that Landrace pigs, which are recognized for their higher lean meat proportion and lower body fat mass as compared to Erhualian pigs, harbored more colonic methanogens (density and diversity). 


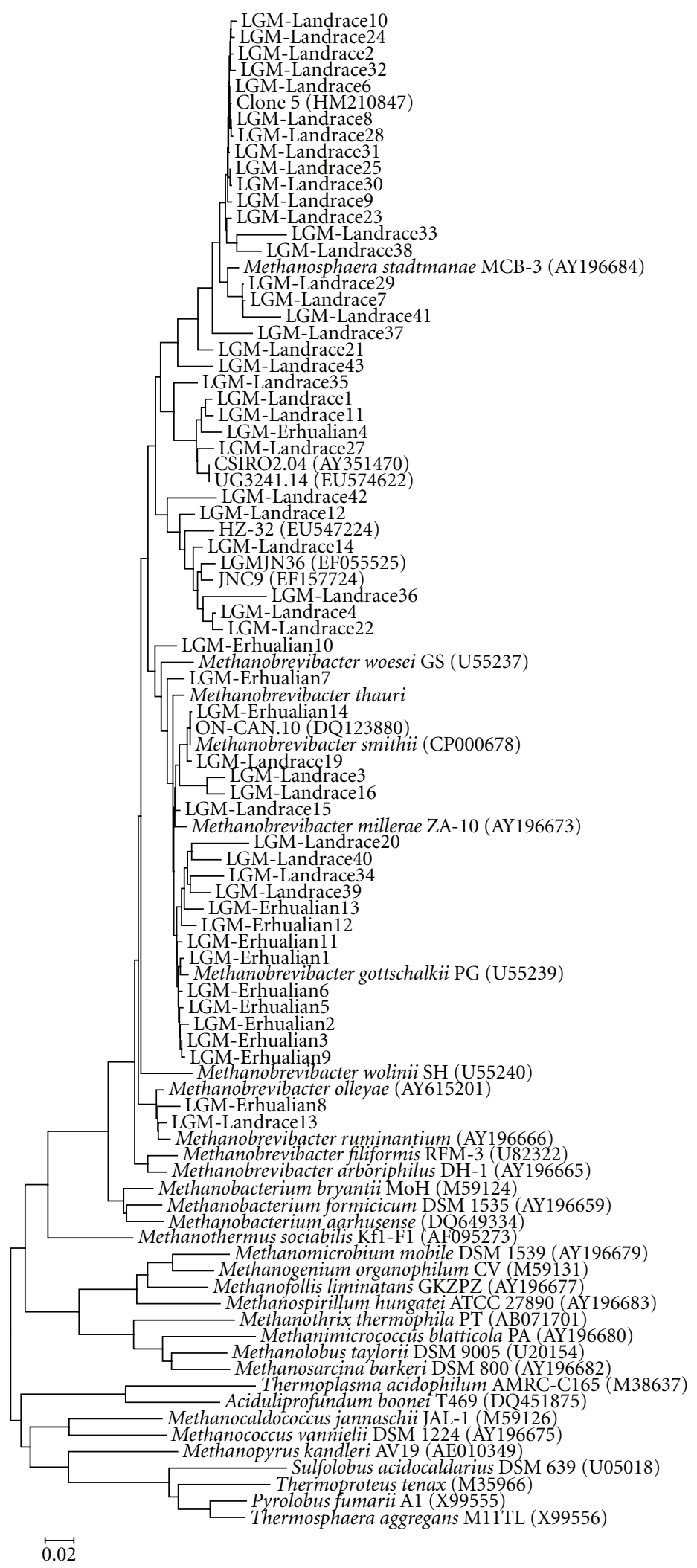

FIGURE 1: Phylogenetic relationship of archaeal 16S rRNA gene sequences retrieved from fecal samples of Erhualian and Landrace pigs. Evolutionary distances were calculated using the Neighbor-Joining method. The tree was bootstrap resampled 1000 times. 
TABLE 2: Comparison of OTUs between Erhualian and Landrace pigs.

\begin{tabular}{|c|c|c|c|c|}
\hline \multirow{2}{*}{ OTU } & \multicolumn{2}{|c|}{ No. of sequences } & \multirow{2}{*}{ Nearest valid taxon* } & \multirow{2}{*}{$\%$ Seq. identity } \\
\hline & Erhualian & Landrace & & \\
\hline 1 & 13 & - & Methanosphaera cuniculi & 96.3 \\
\hline 2 & 5 & - & Methanobrevibacter millerae & 96.9 \\
\hline 3 & 81 & - & Methanobrevibacter ruminantium & 97.1 \\
\hline 4 & 15 & - & Methanobrevibacter ruminantium & 97.1 \\
\hline 5 & 6 & - & Methanobrevibacter gottschalkii & 97.4 \\
\hline 6 & 9 & - & Methanobrevibacter millerae & 97.8 \\
\hline 7 & - & 5 & Methanobrevibacter millerae & 95.3 \\
\hline 8 & - & 6 & Methanobrevibacter smithii & 93.9 \\
\hline 9 & - & 4 & Methanobrevibacter ruminantium & 98.8 \\
\hline 10 & - & 5 & Methanosphaera cuniculi & 95.1 \\
\hline 11 & 141 & 4 & Methanobrevibacter gottschalkii & 98.8 \\
\hline 12 & - & 2 & Methanobrevibacter smithii & 97.0 \\
\hline 13 & 111 & 89 & Methanobrevibacter smithii & 99.9 \\
\hline 14 & - & 43 & Methanobrevibacter smithii & 97.1 \\
\hline 15 & - & 5 & Methanosphaera cuniculi & 94.6 \\
\hline 16 & - & 17 & Methanosphaera stadtmanae & 95.7 \\
\hline 17 & - & 19 & Methanosphaera cuniculi & 94.9 \\
\hline 18 & - & 2 & Methanobrevibacter smithii & 94.2 \\
\hline 19 & - & 10 & Methanosphaera stadtmanae & 97.2 \\
\hline 20 & - & 81 & Methanosphaera cuniculi & 98.1 \\
\hline 21 & - & 12 & Methanosphaera cuniculi & 95.5 \\
\hline 22 & - & 7 & Methanobrevibacter millerae & 97.4 \\
\hline 23 & - & 6 & Methanobrevibacter smithii & 94.5 \\
\hline 24 & - & 6 & Methanosphaera cuniculi & 94.2 \\
\hline 25 & - & 2 & Methanosphaera cuniculi & 95.5 \\
\hline 26 & - & 3 & Methanosphaera cuniculi & 97.4 \\
\hline 27 & - & 1 & Methanobrevibacter millerae & 98.5 \\
\hline 28 & - & 46 & Methanobrevibacter smithii & 96.8 \\
\hline 29 & - & 2 & Methanosphaera stadtmanae & 96.7 \\
\hline 30 & - & 4 & Methanosphaera cuniculi & 95.3 \\
\hline 31 & - & 1 & Methanobrevibacter smithii & 95.3 \\
\hline Totals & 381 & 382 & & \\
\hline
\end{tabular}

* Nearest valid taxon is represented by the type strain of the designated species.

TABLE 3: Coverage and Shannon Index calculated using MOTHUR ${ }^{1}$ for each methanogen $16 S$ rRNA gene clone library.

\begin{tabular}{lccccc}
\hline Clone library & OTUs observed & CHAO 1 OTU estimate & $\%$ OTU coverage & Shannon index \pm 95\% confidence limits & Libshuff analysis \\
\hline Erhualian & 8 & 8 & 100 & $1.51 \pm 0.08^{\mathrm{a}}$ & $P<0.0001$ \\
Landrace & 24 & 24.2 & 99.2 & $2.38 \pm 0.11^{\mathrm{b}}$ & $P<0.0001$ \\
\hline
\end{tabular}

${ }^{1}$ Schloss et al. [21].

${ }^{2}$ Good's [22] coverage $(C)$ according to the equation $C=1-(n / N)$, where $n$ is the number of sequences represented by a single clone and $N$ is the total number of clones in the library.

$\mathrm{a}, \mathrm{b}$ There is significant difference between these values.

Methanogens can produce methane from substrates such as $\mathrm{H}_{2}$ and $\mathrm{CO}_{2}$ and formate, which could also be used for the formation of propionate and acetate. For ruminants, it is widely established that the formation of methane results in a loss of energy available for the host $[33,34]$. Thus, a highly dense and diverse methanogen community as observed in fecal samples may also suggest an energy loss, which may consequently affect energy metabolism and body fat mass formation. It is also possible that although methane formation may represent a small portion of energy for a pig growth, it may affect metabolic pathway network and consequently affect the energy metabolism.

In total, 763 clones were examined from the two $16 \mathrm{~S}$ rRNA gene clone libraries, revealing 53 phylotypes assigned 
to 31 OTUs (Table 1). OTUs 11 and 13 were the only OTUs found in both pig breeds (Table 2) and accounted for 66\% and $24 \%$ of the clones from Erhualian and Landrace pigs, respectively. Interestingly, clones belonging to OTU11 were nearly 35 times higher in Erhualian library than Landarce library. OTUs 11 and 13 combined for $70 \%$ of all OTUs in Erhualian library, but only $36 \%$ of all OTUs in the Landrace library (Table 2).

The comparison of OTUs between the two libraries (Table 2) showed that Methanobrevibacter-like sequences (96.6\%) were dominant in the feces of Erhualian pigs, whereas the proportion was $56.5 \%$ for Landrace pigs. Furthermore, Methanosphaera-like sequences accounted for $3.4 \%$ in Erhualian and $43.5 \%$ in Landrace. This is consistent with previous findings that Methanobrevibacter species are the predominant methanogen in the hindgut of monogastric animals [27, 35-42] or in the rumen of sheep [31, 43-45], cattle [45-48] and also in some cultivation studies [49]. Nevertheless, in the rumen of sheep and bovine, the most dominant methanogens belonged to genus Methanobrevibacter, and the density of Methanosphaera-like species was much less than that of Methanobrevibacterlike species $[45,46]$. While in the rumen of sheep from Western Australia, Methanosphaera stadtmanae was only found in a minority of sheep [31]. In our previous study, the proportion of Methanosphaera stadtmanae 16S rRNA sequences was very small in Duroc $\times$ Landrace $\times$ Yorkshire pig feces [27]. However, in the present study, Landrace pigs had 10 times more Methanosphaera-like methanogens than Erhualian pigs, while Methanosphaera-like species were the second dominant methanogens behind Methanobrevibacter in the feces of both pig breeds.

Our libraries also contained several yet unidentified euryarchaeotic sequences. Fourteen OTUs (LGM-Lal and $11,3,4$ and $22,12,14,21,27,33,35,36,37,42,43$ and LGM-Er4) were most likely represent yet unknown methanogenic species and strains (Table 1). Interestingly, in a previous study we found that populations related to Aciduliprofundum boonei and Thermoplasma acidophilum were present, in addition to the Methanobrevibacter and Methanosphaera populations, in the feces of Duroc $\times$ Landrace $\times$ Yorkshire pigs [27]. Methanogens related to the Thermoplasmatales clade were also found in some ruminants $[19,32,46,50]$, whereas in the current study, most sequences were associated with the two genera Methanobrevibacter and Methanosphaera. This suggests that there might be a difference in the diversity of gut methanogens between pure breeds and hybrids, and hybridization of different breeds might introduce a certain alteration of the methanogenic diversity into the intestine.

\section{Conclusion}

The current study provided the first account on the abundance and phylogenetic diversity of methanogens found in Erhualian (obese) and Landrace (lean) pig feces based on 16S rRNA gene clone library analysis. Landrace pigs have a markedly higher density of methanogens than the Erhualian pigs $(P<0.05)$. The diversity of methanogens of Landrace pigs was also significantly higher than that of Erhualian animals $(P<0.05)$ with Methanobrevibacter as the most dominant genus in both breeds, and Methanosphaera being the second most dominant methanogen in Landrace pigs. The functional roles of these methanogens in the pig gut, and whether observed differences in methanogen diversity and density are related to the pig fat or energy metabolism, need further investigation.

\section{Acknowledgments}

This work was supported by the Natural Science Foundation of China (NSFC) (30810103909), R \& D Special Fund for Public Welfare in Agriculture of China (200903003), and the European Union through the European Frame Work 7 project "INTERPLAY" (Project no. 227549). The authors thank CSIRO Livestock Industry (Australia) for the supply of Methanobrevibacter smithii cells.

\section{References}

[1] J. H. P. Hackstein and T. A. van Alen, "Fecal methanogens and vertebrate evolution," Evolution, vol. 50, no. 2, pp. 559-572, 1996.

[2] B. Morvan, F. Bonnemoy, G. Fonty, and P. Gouet, "Quantitative determination of $\mathrm{H}_{2}$-utilizing acetogenic and sulfatereducing bacteria and methanogenic archaea from digestive tract of different mammals," Current Microbiology, vol. 32, no. 3, pp. 129-133, 1996.

[3] C. Lin and T. L. Miller, "Phylogenetic analysis of Methanobrevibacter isolated from feces of humans and other animals," Archives of Microbiology, vol. 169, no. 5, pp. 397-403, 1998.

[4] G. J. Monteny, C. M. Groenestein, and M. A. Hilhorst, "Interactions and coupling between emissions of methane and nitrous oxide from animal husbandry," Nutrient Cycling in Agroecosystems, vol. 60, no. 1-3, pp. 123-132, 2001.

[5] B. S. Samuel and J. I. Gordon, "A humanized gnotobiotic mouse model of host-archaeal-bacterial mutualism," Proceedings of the National Academy of Sciences of the United States of America, vol. 103, no. 26, pp. 10011-10016, 2006.

[6] F. Bäckhed, J. K. Manchester, C. F. Semenkovich, and J. I. Gordon, "Mechanisms underlying the resistance to dietinduced obesity in germ-free mice," Proceedings of the National Academy of Sciences of the United States of America, vol. 104, no. 3, pp. 979-984, 2007.

[7] F. Armougom, M. Henry, B. Vialettes, D. Raccah, and D. Raoult, "Monitoring bacterial community of human gut microbiota reveals an increase in Lactobacillus in obese patients and Methanogens in anorexic patients," PLOS ONE, vol. 4, no. 9, Article ID e7125, 2009.

[8] M. Million, M. Maraninchi, M. Henry et al., "Obesityassociated gut microbiota is enriched in Lactobacillus reuteri and depleted in Bifidobacterium animalis and Methanobrevibacter smithii," International Journal of Obesity. In press.

[9] H. Zhang, J. K. DiBaise, A. Zuccolo et al., "Human gut microbiota in obesity and after gastric bypass," Proceedings of the National Academy of Sciences of the United States of America, vol. 106, no. 7, pp. 2365-2370, 2009.

[10] X. Pang, X. Hua, Q. Yang et al., "Inter-species transplantation of gut microbiota from human to pigs," ISME Journal, vol. 1, no. 2, pp. 156-162, 2007. 
[11] A. A. Jiang, M. Z. Li, K. Zhang, Y. R. Gu, and X. W. Li, "Expression changes of PPARGC1A during the development of lean and obese pigs," Journal of Animal and Veterinary Advances, vol. 10, no. 5, pp. 597-600, 2011.

[12] J. Guo, T. Shan, T. Wu et al., "Comparisons of different muscle metabolic enzymes and muscle fiber types in Jinhua and Landrace pigs," Journal of Animal Science, vol. 89, no. 1, pp. 185-191, 2011.

[13] Z. Q. Ren, Y. Z. Xiong, C. Y. Deng, and S. W. Jiang, "Effects of ATP citrate lyase and adipose differentiation-related protein gene polymorphisms on adipose deposition and meat quality traits in pigs," Journal of Animal and Veterinary Advances, vol. 10, pp. 1610-1615, 2011.

[14] Z. Ren, Y. Xiong, C. Deng, and S. Jiang, "Cloning, differential expression, and association analysis with fat traits of porcine IDH3ã Gene," Applied Biochemistry and Biotechnology, vol. 166, pp. 1112-1120, 2012.

[15] G. Yang, Pig Production, Chinese Agricultural Press, Beijing, China, 1st edition, 2003.

[16] X. Guo, X. Xia, R. Tang, J. Zhou, H. Zhao, and K. Wang, "Development of a real-time PCR method for Firmicutes and Bacteroidetes in faeces and its application to quantify intestinal population of obese and lean pigs," Letters in Applied Microbiology, vol. 47, no. 5, pp. 367-373, 2008.

[17] E. G. Zoetendal, A. D. L. Akkermans, and W. M. de Vos, "Temperature gradient gel electrophoresis analysis of $16 \mathrm{~S}$ rRNA from human fecal samples reveals stable and host-specific communities of active bacteria," Applied and Environmental Microbiology, vol. 64, no. 10, pp. 3854-3859, 1998.

[18] A. D. G. Wright and C. Pimm, "Improved strategy for presumptive identification of methanogens using $16 \mathrm{~S}$ riboprinting," Journal of Microbiological Methods, vol. 55, no. 2, pp. 337-349, 2003.

[19] C. X. Pei, S. Y. Mao, Y. F. Cheng, and W. Y. Zhu, "Diversity, abundance and novel 16S rRNA gene sequences of methanogens in rumen liquid, solid and epithelium fractions of Jinnan cattle," Animal, vol. 4, no. 1, pp. 20-29, 2010.

[20] A. D. G. Wright, K. S. Northwood, and N. E. Obispo, "Rumenlike methanogens identified from the crop of the folivorous South American bird, the hoatzin (Opisthocomus hoazin)," ISME Journal, vol. 3, no. 10, pp. 1120-1126, 2009.

[21] P. D. Schloss, S. L. Westcott, T. Ryabin et al., "Introducing mothur: open-source, platform-independent, communitysupported software for describing and comparing microbial communities," Applied and Environmental Microbiology, vol. 75, no. 23, pp. 7537-7541, 2009.

[22] I. J. Good, "The population frequencies of species and the estimation of population parameters," Biometrika, vol. 40, pp. 237-264, 1953.

[23] S. F. Altschul, T. L. Madden, A. A. Schäffer et al., "Gapped BLAST and PSI-BLAST: a new generation of protein database search programs," Nucleic Acids Research, vol. 25, no. 17, pp. 3389-3402, 1997.

[24] J. Felsenstein, PHYLIP (Phylogeny Inference Package) Documentation Files. Version 3.62c, Department of Genetics, University of Washington, Seattle, Wash, USA, 2004.

[25] S. E. Denman, N. W. Tomkins, and C. S. McSweeney, "Quantitation and diversity analysis of ruminal methanogenic populations in response to the antimethanogenic compound bromochloromethane," FEMS Microbiology Ecology, vol. 62, no. 3, pp. 313-322, 2007.

[26] P. N. Evans, L. A. Hinds, L. I. Sly, C. S. McSweeney, M. Morrison, and A. D. G. Wright, "Community composition and density of Methanogens in the foregut of the Tammar wallaby
(Macropus eugenii)," Applied and Environmental Microbiology, vol. 75, no. 8, pp. 2598-2602, 2009.

[27] S. Y. Mao, C. F. Yang, and W. Y. Zhu, "Phylogenetic analysis of methanogens in the pig feces," Current Microbiology, vol. 62, no. 5, pp. 1386-1389, 2011.

[28] E. E. King, R. P. Smith, B. St-Pierre, and A. D. G. Wright, "Differences in the rumen methanogen populations of lactating Jersey and Holstein dairy cows under the same diet regimen," Applied and Environmental Microbiology, vol. 77, pp. 56825687, 2011.

[29] M. A. Sundset, J. E. Edwards, Y. F. Cheng et al., "Molecular diversity of the rumen microbiome of norwegian reindeer on natural summer pasture," Microbial Ecology, vol. 57, no. 2, pp. 335-348, 2009.

[30] S. E. Hook, K. S. Northwood, A. D. G. Wright, and B. W. McBride, "Long-term monensin supplementation does not significantly affect the quantity or diversity of methanogens in the rumen of the lactating dairy cow," Applied and Environmental Microbiology, vol. 75, no. 2, pp. 374-380, 2009.

[31] A. D. G. Wright, A. J. Williams, B. Winder, C. T. Christophersen, S. L. Rodgers, and K. D. Smith, "Molecular diversity of rumen methanogens from sheep in Western Australia," Applied and Environmental Microbiology, vol. 70, no. 3, pp. 1263-1270, 2004.

[32] A. D. G. Wright, C. H. Auckland, and D. H. Lynn, "Molecular diversity of methanogens in feedlot cattle from Ontario and Prince Edward Island, Canada," Applied and Environmental Microbiology, vol. 73, no. 13, pp. 4206-4210, 2007.

[33] K. A. Johnson and D. E. Johnson, "Methane emissions from cattle," Journal of Animal Science, vol. 73, no. 8, pp. 2483-2492, 1995.

[34] A. Machmüller, D. A. Ossowski, and M. Kreuzer, "Comparative evaluation of the effects of coconut oil, oilseeds and crystalline fat on methane release, digestion and energy balance in lambs," Animal Feed Science and Technology, vol. 85, no. 1-2, pp. 41-60, 2000.

[35] T. L. Miller, M. J. Wolin, E. C. de Macario, and A. J. L. Macario, "Isolation of Methanobrevibacter smithii from human feces," Applied and Environmental Microbiology, vol. 43, no. 1, pp. 227-232, 1982.

[36] T. L. Miller, G. A. Weaver, and M. J. Wolin, "Methanogens and anaerobes in a colon segment isolated from the normal fecal stream," Applied and Environmental Microbiology, vol. 48, no. 2, pp. 449-450, 1984.

[37] T. L. Miller and M. J. Wolin, "Enumeration of Methanobrevibacter smithii in human feces," Archives of Microbiology, vol. 131, no. 1, pp. 14-18, 1982.

[38] T. L. Miller and M. J. Wolin, "Oxidation of hydrogen and reduction of methanol to methane is the sole energy source for a methanogen isolated from human feces," Journal of Bacteriology, vol. 153, no. 2, pp. 1051-1055, 1983.

[39] R. P. Kiene, R. S. Oremland, A. Catena, L. G. Miller, and D. G. Capone, "Metabolism of reduced methylated sulfur compounds in anaerobic sediments and by a pure culture of an estuarine methanogen," Applied and Environmental Microbiology, vol. 52, pp. 1037-1045, 1986.

[40] G. A. Weaver, J. A. Krause, T. L. Miller, and M. J. Wolin, "Incidence of methanogenic bacteria in a sigmoidoscopy population: an association of methanogenic bacteria and diverticulosis," Gut, vol. 27, no. 6, pp. 698-704, 1986.

[41] J. R. Leadbetter and J. A. Breznak, "Physiological ecology of Methanobrevibacter cuticularis sp. nov. and Methanobrevibacter curvatus sp. nov., isolated from the hindgut of 
the termite Reticulitermes flavipes," Applied and Environmental Microbiology, vol. 62, no. 10, pp. 3620-3631, 1996.

[42] J. R. Leadbetter, L. D. Crosby, and J. A. Breznak, "Methanobrevibacter filiformis sp. nov., a filamentous methanogen from termite hindguts," Archives of Microbiology, vol. 169, no. 4, pp. 287-292, 1998.

[43] A. D. G. Wright, X. Ma, and N. E. Obispo, "Methanobrevibacter phylotypes are the dominant methanogens in sheep from Venezuela," Microbial Ecology, vol. 56, no. 2, pp. 390-394, 2008.

[44] L. C. Skillman, P. N. Evans, G. E. Naylor, B. Morvan, G. N. Jarvis, and K. N. Joblin, "16S ribosomal DNA-directed PCR primers for ruminal methanogens and identification of methanogens colonising young lambs," Anaerobe, vol. 10, no. 5, pp. 277-285, 2004.

[45] M. J. Nicholson, P. N. Evans, and K. N. Joblin, "Analysis of methanogen diversity in the rumen using temporal temperature gradient gel electrophoresis: identification of uncultured methanogens," Microbial Ecology, vol. 54, no. 1, pp. 141-150, 2007.

[46] M. F. Whitford, R. M. Teather, and R. J. Forster, "Phylogenetic analysis of methanogens from the bovine rumen," $B M C$ Microbiology, vol. 1, article 5, 2001.

[47] L. C. Skillman, P. N. Evans, C. Strömpl, and K. N. Joblin, "16S rDNA directed PCR primers and detection of methanogens in the bovine rumen," Letters in Applied Microbiology, vol. 42, no. 3, pp. 222-228, 2006.

[48] D. Ouwerkerk, A. F. Turner, and A. V. Klieve, "Diversity of methanogens in ruminants in Queensland," Australian Journal of Experimental Agriculture, vol. 48, no. 7, pp. 722-725, 2008.

[49] T. L. Miller, M. J. Wolin, Z. Hongxue, and M. P. Bryant, "Characteristics of methanogens isolated from bovine rumen," Applied and Environmental Microbiology, vol. 51, no. 1, pp. 201-202, 1986.

[50] A. D. G. Wright, A. F. Toovey, and C. L. Pimm, "Molecular identification of methanogenic archaea from sheep in Queensland, Australia reveal more uncultured novel archaea," Anaerobe, vol. 12, no. 3, pp. 134-139, 2006. 

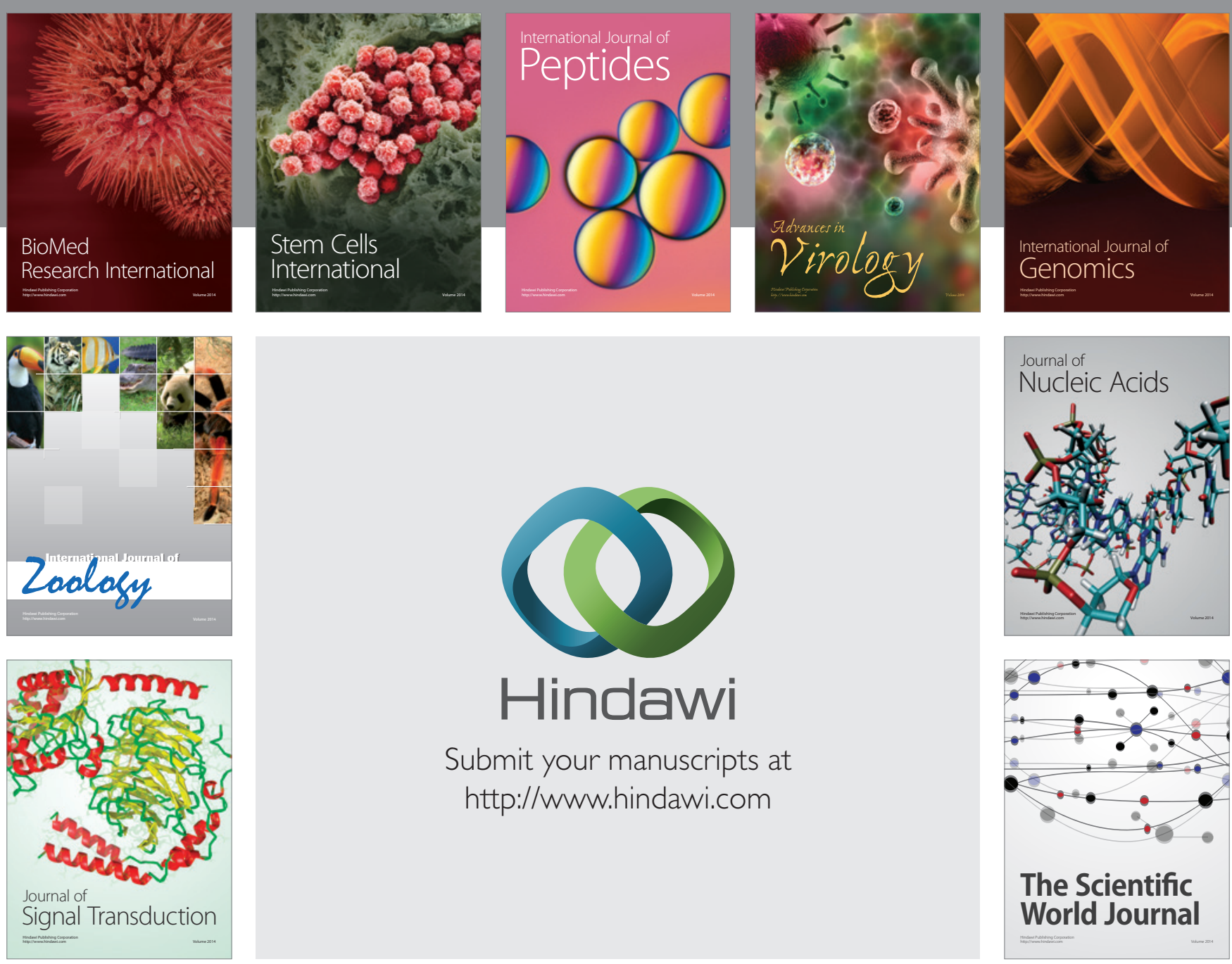

Submit your manuscripts at

http://www.hindawi.com
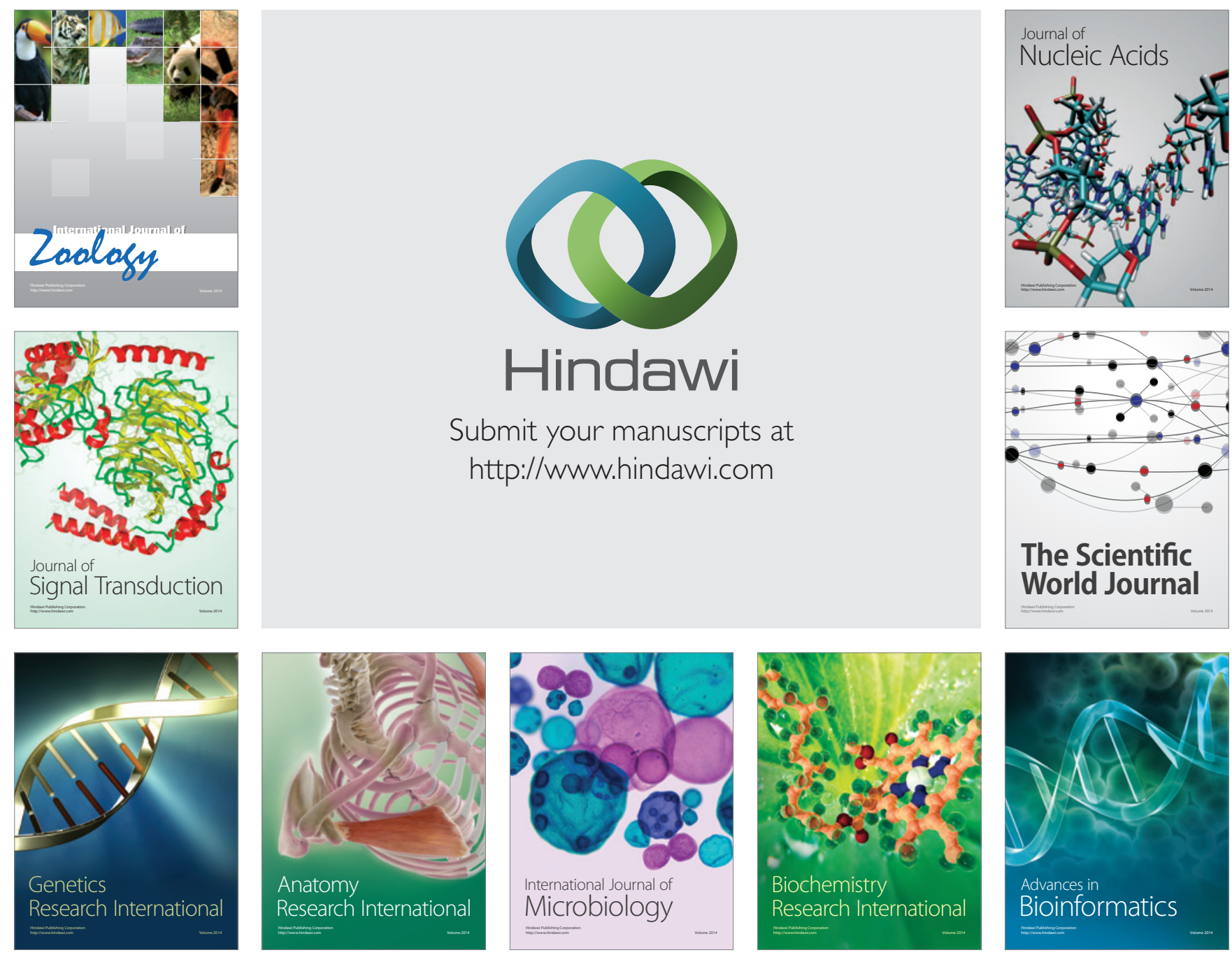

The Scientific World Journal
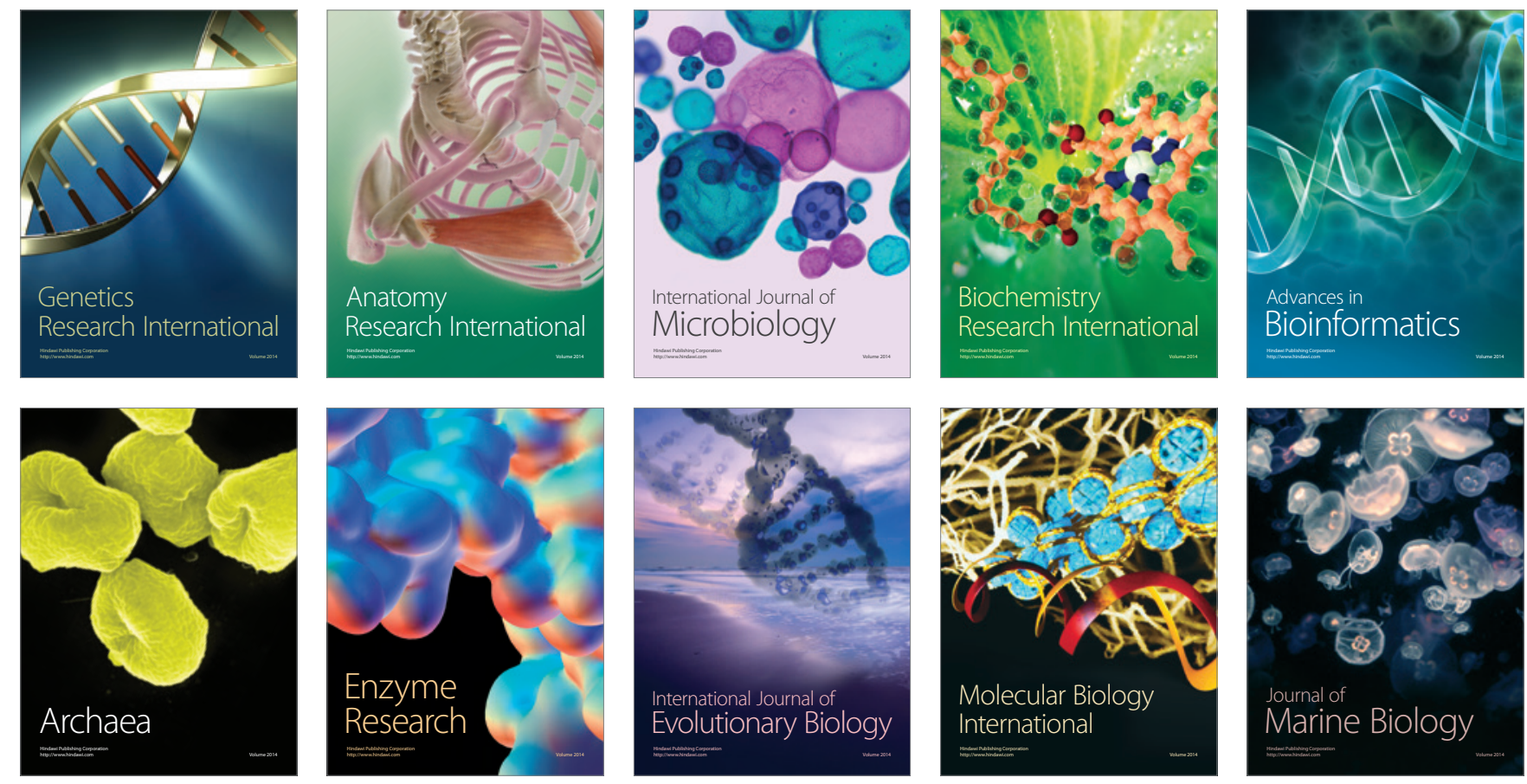